\title{
The role of iNOS in cholesterol-induced liver fibrosis
}

\author{
Sarit Anavi ${ }^{1}$, Michal Eisenberg-Bord ${ }^{1}$, Michal Hahn-Obercyger ${ }^{1}$, Olga Genin², Mark Pines $^{2}$ and Oren Tirosh ${ }^{1}$
}

Accumulation of cholesterol in the liver is associated with the development of non-alcoholic steatohepatitis-related fibrosis. However, underlying mechanisms are not well understood. The present study investigated the role of inducible nitric oxide synthase (iNOS) in cholesterol-induced liver fibrosis by feeding wild-type (WT) and iNOS-deficient mice with control or high-cholesterol diet (HCD) for 6 weeks. WT mice fed with HCD developed greater liver fibrosis, compared with iNOS-deficient mice, as evident by Sirius red staining and higher expression levels of profibrotic genes. Enhanced liver fibrosis in the presence of iNOS was associated with hypoxia-inducible factor- $1 \alpha$ stabilization, matrix metalloproteinase- 9 expression, and enhanced hepatic DNA damage. The profibrotic role of iNOS was also demonstrated in vivo using a selective inhibitor of iNOS as well as in vitro in a rat liver stellate cell line (HSC-T6). In conclusion, these findings suggest that iNOS is an important mediator in HCD-induced liver fibrosis.

Laboratory Investigation (2015) 95, 914-924; doi:10.1038/labinvest.2015.67; published online 22 June 2015

Non-alcoholic fatty liver disease (NAFLD) is currently one of the most common liver diseases worldwide, affecting both adults and children. The disease encompasses a wide spectrum of liver damage ranging from simple hepatic steatosis and non-alcoholic steatohepatitis (NASH) to liver cirrhosis and increased risk for developing hepatocellular carcinoma. Pathological characterization of NASH includes the presence of steatosis and inflammation and recently it has also been recognized as a major cause of liver fibrosis. Liver fibrosis represents the liver's wound healing response to virtually all forms of chronic liver injury. This dynamic process involves the accumulation of the extracellular matrix (ECM) following injury. Under acute or limited insults, parenchymal cells regenerate and replace the necrotic or apoptotic cells. However, if the liver injury is sustained, regeneration fails and liver parenchymal cells are substituted by scar tissue. ${ }^{1,2}$

Fibrosis associated with NASH has been suggested to be the physiological consequence of chronic hepatic injury, necrosis, and inflammation as well as unbalanced intrahepatic lipid metabolism (steatosis), insulin resistance, oxidative stress, and lipid peroxidation. ${ }^{3-5}$

Different lipid molecules may mediate the pathogenesis and the progression of NASH. To date, the identity of a dominant lipid molecule/s, which causes liver lipotoxicity, is still unknown. Recently, attention has been given to the role of hepatic cholesterol content in NASH pathology. ${ }^{6-10}$ Evidence collected from both human and animal models of NASH point to cholesterol as a potential mediator of lipotoxicity in NASH, including the development of hepatic fibrosis. In the first National Health and Nutrition Examination Survey in the United States, dietary cholesterol consumption was positively associated with the risk of cirrhosis or liver cancer. Consistent with these findings, cholesterol-lowering agents, such as statins and ezetimibe, were shown to improve liver fibrosis among patients with hypercholesterolemia and mice with NASH. ${ }^{8-11}$ Enhanced liver fibrosis is also evident in experimental studies conducted in rodents and rabbits following the consumption of a highcholesterol diet (HCD) containing cholic acid or a high-fat/ HCD diet or methionine-choline-deficient diet supplemented with cholesterol. ${ }^{8,9}$

Initiation of chronic liver diseases commonly involves an inflammatory phase, which progresses to fibrosis after continuous oxidative stress. Under these conditions inducible nitric oxide synthase (iNOS) is upregulated, leading to the production of large amounts of nitric oxide (NO). ${ }^{12}$ The role of iNOS in fibrosis formation is not clearly understood. Data from animal models of fibrosis or NASH-related liver fibrosis have shown conflicting results of both beneficial and deleterious effects of iNOS. ${ }^{12-19}$ The exact reason/s for these paradoxical effects is difficult to explain. Therefore, the

\footnotetext{
${ }^{1}$ Institute of Biochemistry, Food Science and Nutrition, The Robert H. Smith Faculty of Agriculture, Food and Environment, The Hebrew University of Jerusalem, Rehovot, Israel and ${ }^{2}$ Institute of Animal Sciences, Volcani Center, Bet Dagan, Israel

Correspondence: Professor O Tirosh, Ph.D, The Robert H. Smith Faculty of Agriculture, Food and Environment, Institute of Biochemistry Food Science and Nutrition, The Hebrew University of Jerusalem, PO Box 12, Rehovot 76100 Israel.

E-mail: oren.tirosh@mail.huji.ac.il
}

Received 14 October 2014; revised 7 April 2015; accepted 28 April 2015 
present study was undertaken to elucidate the role of iNOS in the pathophysiology of liver fibrosis due to consumption of a HCD.

\section{MATERIALS AND METHODS \\ Animal Experiments}

Adult male wild-type (WT) C57BL/6J mice and C57BL/6J iNOS-deficient (iNOS-/-) mice were purchased from Harlan Laboratories, (Jerusalem, Israel) and Jackson Laboratories (Bar Harbor, ME), respectively. Mice were maintained in a temperature- and light-controlled facility, and permitted ad libitum consumption of water and pellet chow. Experiment 1 (genetic inhibition of iNOS): WT and iNOS-deficient mice were fed with standard diet ( $n=3-4$ per group) or with $\mathrm{HCD}$ ( $1 \%$ cholesterol $+0.5 \%$ cholic acid, $n=6-7$ per group). Experiment 2 (pharmacological inhibition of iNOS): WT mice were fed a standard diet or HCD with or without the addition of iNOS-specific inhibitor S,S'-1,3-phenylene-bis (1,2-ethanediyl)-bis-isothiourea dihydrobromide (PBIT, 100 p.p.m. in diet, $n=7-9$ per group). In both experiments, after 6 weeks of diet consumption, animals were killed to obtain plasma and liver tissue. All animals received humane care, and all study protocols were approved by Institutional Animal Care and Use Committee.

\section{Blood Parameters and Biochemical Analyses}

Analysis of plasma alanine aminotransferase (ALT/SGPT) and aspartate aminotransferase (AST/SGOT) levels were performed by American Laboratories (Hertzlia, Israel). Total lipid was extracted from livers using the Folch method. ${ }^{20}$ Cholesterol levels were determined colorimetric following saponification. In brief, about $4 \mathrm{ml}$ of absolute ethanol and $1 \mathrm{ml} 60 \% \mathrm{KOH}$ were added to samples and mixed thoroughly. The capped tubes were placed in $65^{\circ} \mathrm{C}$ water bath for $1 \mathrm{~h}$. After cooling to room temperature, $3 \mathrm{ml}$ of distilled water were added and the non-saponifiables were extracted twice with petrol ether. Following petrol ether evaporation, cholesterol was quantified using a color reagent of glacial acetic acid- $\mathrm{FeSO}_{4}-\mathrm{H}_{2} \mathrm{SO}_{4}$. The absorbance of the cooled, color mixture was read at $490 \mathrm{~nm}$ against the reagent blank.

\section{Liver Histology and Immunohistochemistry}

Livers were fixed in $4 \%$ formaldehyde (Bio-Lab, Jerusalem, Israel), and microtome (Leica Microsystems) sections ( $5 \mu \mathrm{m})$ were prepared. Hematoxylin and eosin staining was used for tissue section visualization and Sirius red was used to stain collagen in tissue sections. Immunohistochemistry was done with anti-proliferating cell nuclear antigen (PCNA) or alpha smooth muscle actin $(\alpha \mathrm{SMA})$ antibodies.

\section{Quantitative Real-Time PCR}

Total RNA was isolated using the Tri-Reagent (Sigma-Aldrich, Israel) method, according to the manufacturer's protocol. Complementary DNA was prepared using a high-capacity cDNA Reverse Transcription kit (Applied Biosystems, Foster
City, CA, USA). Real-time PCR was performed using the 7300 real-time PCR System (Applied Biosystems, Warrington, UK) using specific primers (Supplementary Information). Fold change in gene expression was determined by normalizing to $18 S$ mRNA.

\section{Protein Extraction and Western Blot Analyses}

Whole-cell lysates were prepared in RIPA buffer and nuclear extracts were prepared as previously described..$^{21}$ Aliquots of protein were then subjected to western blot analysis. Ponceau $S$ (Sigma) staining was used to verify equal loading and transfer. Primary antibodies used were: iNOS (BD Biosciences), hypoxia-inducible factor 1(HIF-1) $\alpha$ (Novus Biologicals), $\alpha$ SMA, matrix metalloproteinase-9 (MMP-9; Abcam), and histone 2AX (H2AX) phospho-specific (Ser139; Cell Signaling Technology). Secondary antibodies were obtained from Jackson ImmunoResearch (West Grove, PA).

\section{Gelatin Zymography}

Gelatinolytic activity of liver homogenates was examined by gelatin zymography as described previously. ${ }^{22}$

\section{Cell Culture and Treatments}

HSC-T6 cells, an immortalized cell line of rat hepatic stellate cells (HSCs; generously provided by Dr S.L. Friedman), were maintained at $37^{\circ} \mathrm{C}$ in $5 \% \mathrm{CO}_{2}$ in Dulbecco's modified Eagles medium supplemented with $10 \%$ heat inactivated FBS, $1 \times$ glutamine, penicillin $(100 \mathrm{U} / \mathrm{ml})$, and streptomycin $(100 \mathrm{mg} / \mathrm{ml})$. Approximately $24 \mathrm{~h}$ after seeding, HSC-T6 cells were washed twice with PBS, and the medium was replaced by serum-free medium. HSCs were then incubated with or without water-soluble cholesterol $(50 \mu \mathrm{M})$ for $24 \mathrm{~h}$. $\mathrm{N}$-nitroL-arginine methyl ester hydrochloride (L-NAME; 0-2 mM) was used to inhibit iNOS. Alternatively, cells were incubated with the NO donor, DETA-NONOate $(1 \mathrm{mM})$ for $0-12 \mathrm{~h}$.

\section{Statistical Analysis}

Statistical analysis was performed using the multiple groups. Student's $t$-test. Data are expressed as mean \pm s.e.m., and $P<0.05$ was considered statistically significant.

\section{RESULTS}

Effects of HCD on Liver Steatosis in WT and iNOSDeficient Mice

Following consumption of the HCD, a marked activation of iNOS was observed in WT mice, whereas no protein expression was observed in iNOS-deficient mice (Figure 1a). However, as shown in Figure 1b, HCD induced similar levels of liver steatosis in both the groups of mice. HCD feeding also led to increased liver weights in the WT and iNOS-deficient mice, whereas total body weights were decreased, leading to higher liver to body weight ratio. It should be noted that liver weight and liver to body weight ratio were slightly, but significantly, lower in HCD-fed iNOS-deficient mice (Figure 1c). Conversely, total lipids and cholesterol contents 
a
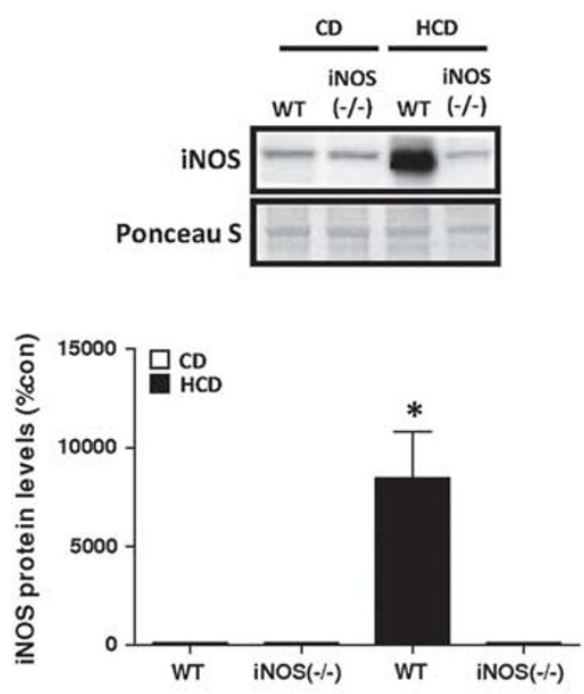

c

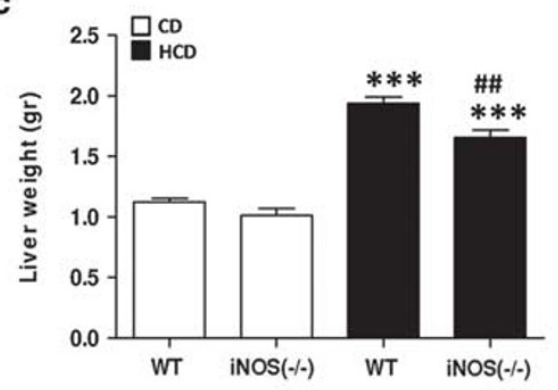

f

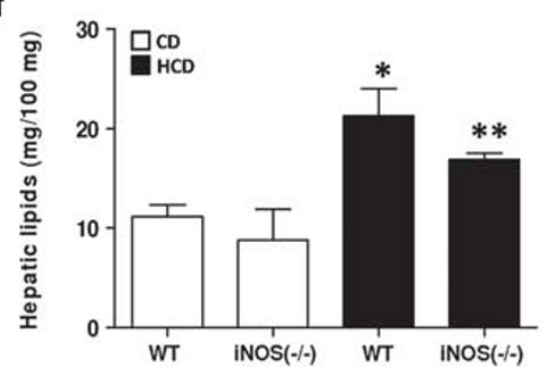

b

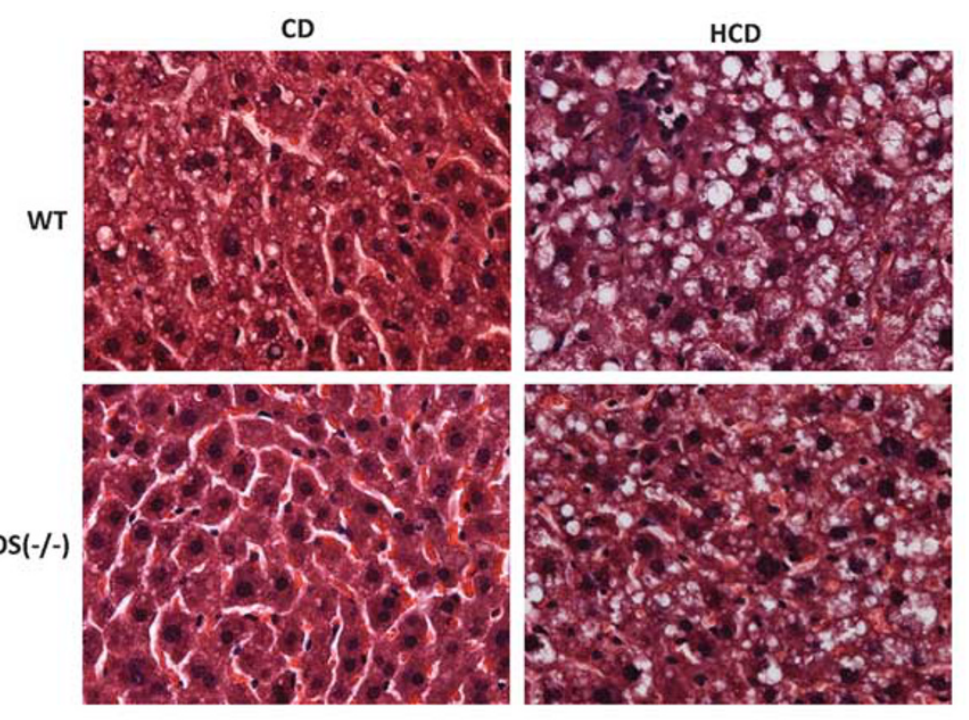

d
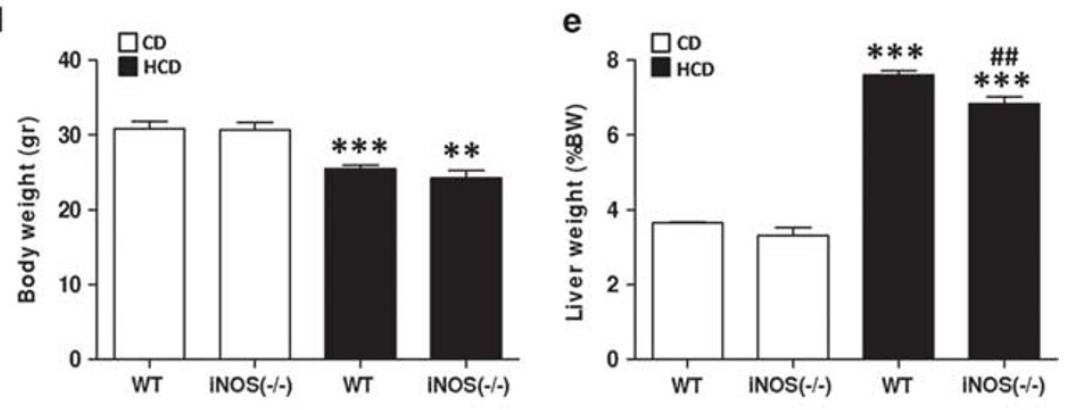

g

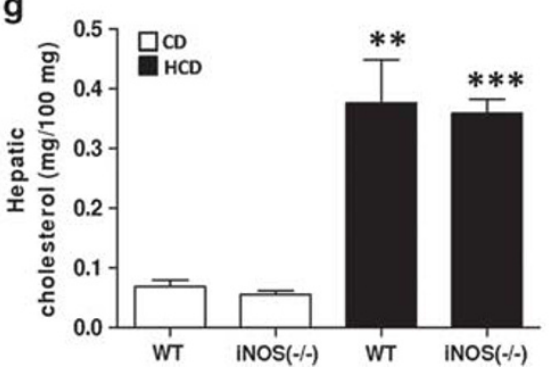

Figure 1 Effects of high-cholesterol diet (HCD) on liver steatosis in wild-type (WT) and iNOS-deficient mice (iNOS(-/-)). WT and iNOS-deficient mice were fed with control diet (CD) ( $n=3-4$, white bars) or HCD ( $n=6-7$, black bars) for 6 weeks. (a) iNOS protein levels. (b) Hematoxylin and eosin (H\&E)stained sections of representative liver samples. (c) Liver weight (g); (d) body weight (BW) (g); (e) liver weight (\% BW); and hepatic (f) lipids and (g) cholesterol levels. Results are means \pm s.e.m. ${ }^{*} P \leq 0.05,{ }^{* *} P \leq 0.01,{ }^{* * *} P \leq 0.001$ vs WT fed with $C D ;{ }^{\# \#} P \leq 0.01$ vs WT fed with HCD. NS, not specific.

did not significantly differ between WT and iNOS-deficient mice following HCD administration (Figure if and g).

\section{Effects of HCD on Liver Damage and Fibrosis in WT and iNOS-Deficient Mice}

Liver damage, as evaluated by plasma liver enzyme levels, increased in both the HCD-fed groups (Figure 2a and b). Liver samples were then stained with Sirius red to evaluate the development of tissue fibrosis. In control groups of WT and iNOS-deficient mice, staining was only observed in areas surrounding the blood vessels. In HCD-fed WT mice, extensive intralobular liver fibrosis was observed. iNOS-deficient mice fed with the same diet demonstrated much less fibrosis (Figure 2c). Consistent with these findings, the expression levels of collagen type- 1 and the profibrotic cytokine tumor necrosis factor $\alpha(\mathrm{TNF} \alpha)$ and transforming growth factor $\beta 1$ (TGF- $\beta 1$ ) were also induced to a greater extent in HCD-fed WT mice compared with HCD-fed iNOS-deficient mice (Figure 2d-f). Overall, $\alpha$ SMA protein levels tended to be lower in HCD-fed iNOS-deficient mice compared with WT mice fed with the same diet, as was demonstrated by western blot (Figure $2 \mathrm{~g}$ ). However, significant variability in protein levels in this group 

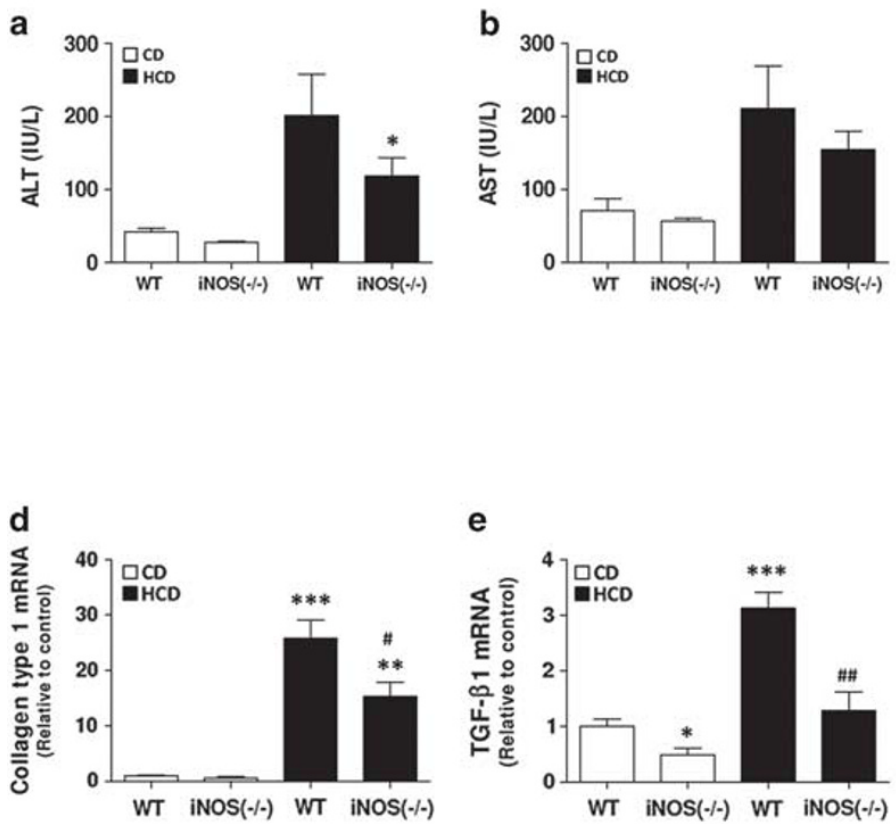

e

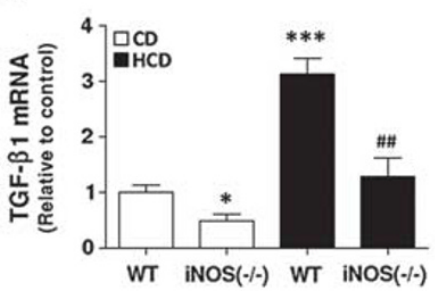

c
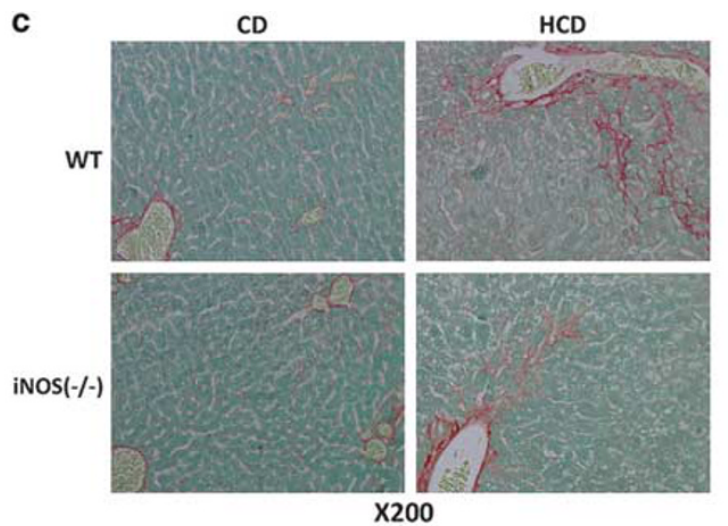

g

f
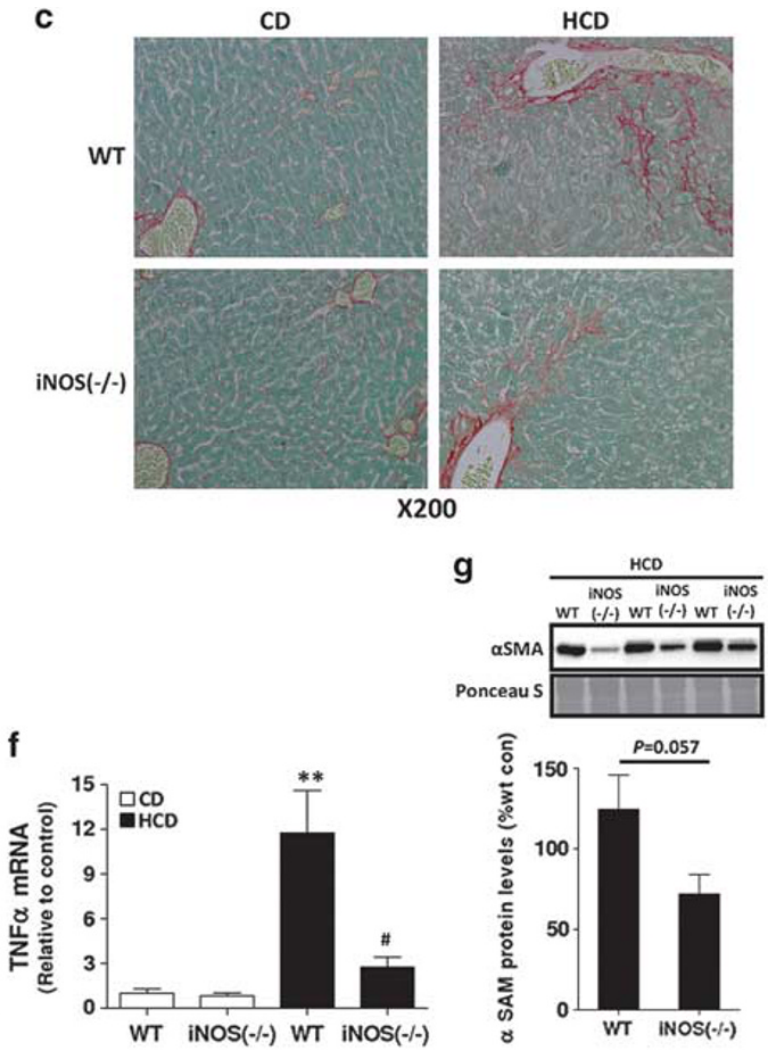

Figure 2 Effects of high-cholesterol diet (HCD) on liver damage and fibrosis in wild-type (WT) and iNOS-deficient mice (iNOS(-/-)). WT and iNOSdeficient mice fed with control diet (CD) ( $n=3-4$, white bars) or HCD ( $n=6-7$, black bars) for 6 weeks. Plasma levels of (a) ALT and (b) AST. (c) Sirius red stained sections of representative liver samples. Hepatic mRNA expression levels of (d) collagen type 1 (e), transforming growth factor- $\beta 1$ (TGF- $\beta 1$ ), (f) tumor necrosis factor- $a$ (TNF-a), and (g) a-smooth muscle actin (a-SMA) protein levels. Results are means \pm s.e.m. ${ }^{*} P \leq 0.05,{ }^{* *} P \leq 0.01,{ }^{* * *} P \leq 0.001$ vs WT fed with $C D ;{ }^{\#} P \leq 0.05,{ }^{\# \#} P \leq 0.01$ vs WT fed with HCD.

was observed. Variance was also high in immunohistochemistry analysis (Supplementary Figure S1).

\section{Effects of HCD on HIF-1 Activation in WT and iNOS-Deficient Mice}

We have recently demonstrated the importance of iNOS in HIF- $1 \alpha$ stabilization and accumulation. ${ }^{23,24}$ Consistent with previous findings, in the current study HIF- $1 \alpha$ was significantly increased in HCD-fed WT mice and was higher than in iNOS-deficient mice (Figure 3a). The elevated HIF-1 induction in HCD-fed WT mice was concomitant with a greater increase in the expression of profibrotic genes, ie, platelet-derived growth factor (PDGF)-A, PDGF-B, fibroblast growth factor-2 (FGF-2), and a trend toward higher plasminogen activator inhibitor-1 (PAI-1) expression, all of which were previously shown to be regulated in HIF- $1 \alpha$-dependent manner (Figure $3 \mathrm{~b}-\mathrm{e}$ ). These results demonstrate the importance of the HIF/iNOS axis in HCD-induced liver fibrosis.

\section{Effects of HCD on MMP-2 and MMP-9 Activation in WT and iNOS-Deficient Mice}

Compelling evidence has documented the association of MMPs with liver fibrosis. ${ }^{25,26}$ MMP-2 and MMP-9 expression was significantly enhanced by HCD in WT mice, whereas only MMP-2 expression was significantly increased in iNOSdeficient mice. Yet, as shown in Figure $4 \mathrm{a}$ and b, both MMPs gene expression was significantly lower in the iNOS-deficient group compared with WT mice. MMP-9, but not MMP-2, activity was much lower in HCD-fed iNOS-deficient mice, compared with WT mice that were fed with the same diet. Moreover, the activity of high-molecular weight gelatinase, which was previously identified as an MMP-9 dimer, was also increased to a greater extent in HCD-fed WT mice (Figure 4c-e). Along with these changes in MMP-9 expression and activity, MMP-9 protein levels also tended to be lower in iNOS-deficient mice (Supplementary Figure S2).

\section{Effects of Pharmacological Inhibition of iNOS in HCD-Induced Liver Fibrosis}

The role of iNOS in HCD-induced liver fibrosis, and specifically in MMP-9 activation under this feeding regime, was further tested using a highly selective and potent iNOSspecific inhibitor (PBIT), ${ }^{27}$ which temporarily blocked iNOS activity during HCD consumption. Both control and PBITtreated mice exhibited higher liver weight following the consumption of HCD (Figure 5a-c). Similarly, liver damage, 
a
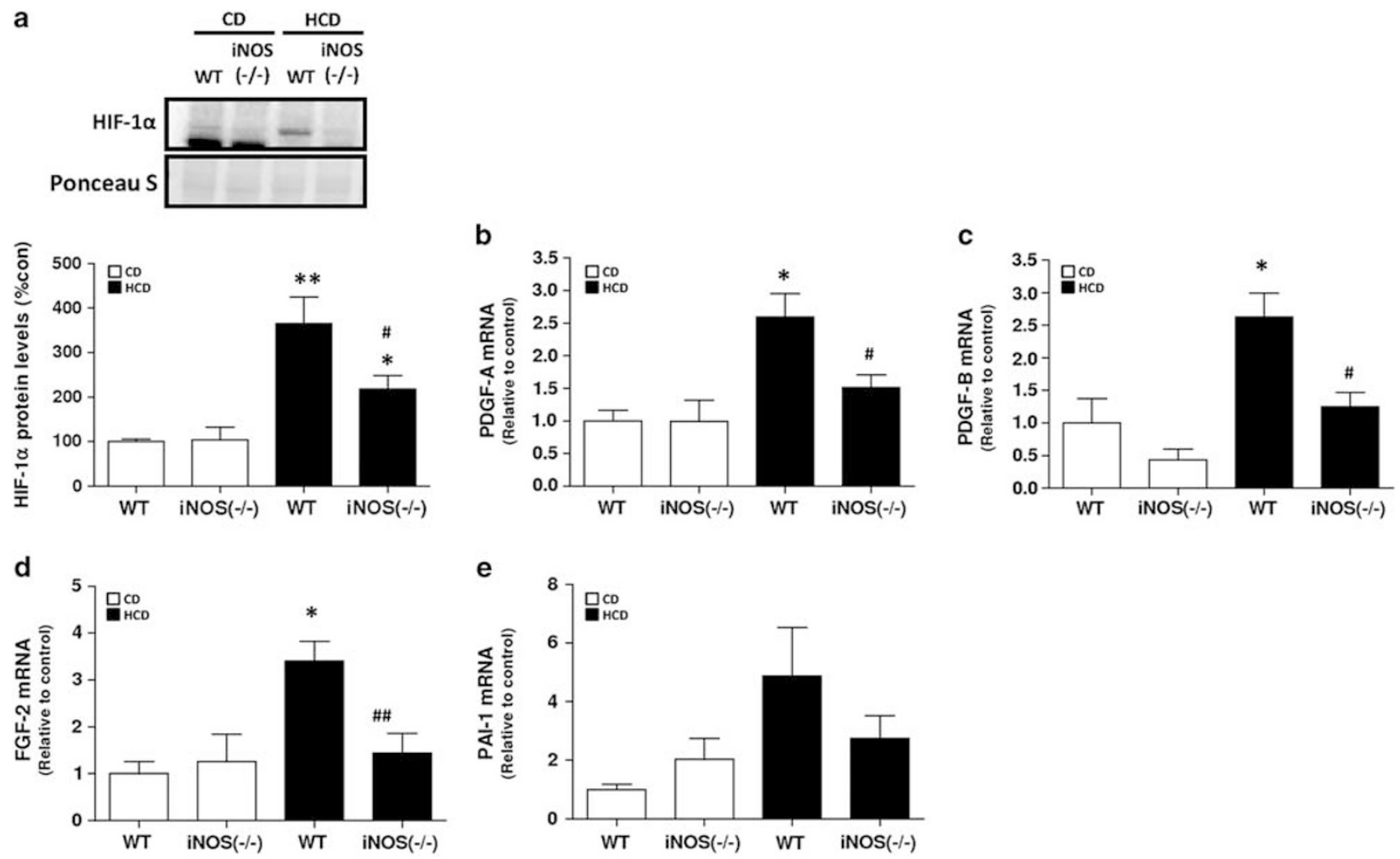

Figure 3 Effects of high-cholesterol diet (HCD) on liver hypoxia inducible factor-1 (HIF-1) activation in wild-type (WT) and iNOS deficient mice (iNOS $(-/-)$ ). WT and iNOS deficient mice fed with control diet (CD) ( $n=3-4$, white bars) or HCD ( $n=6-7$, black bars) for 6 weeks. (a) HIF-1a protein levels in the nucleus and hepatic mRNA expression levels of HIF-1 target genes (b) platelet-derived growth factor (PDGF)-A (c) PDGF-B (d) fibroblast growth factor-2 (FGF-2) (e) plasminogen activator inhibitor-1 (PAl-1). Results are means \pm s.e.m. ${ }^{*} p \leq 0.05,{ }^{* *} p \leq 0.01$ vs. WT fed with CD; ${ }^{\#} p \leq 0.05,{ }^{\# \#} p \leq 0.01$ vs. WT fed with HCD. NS, not specific.
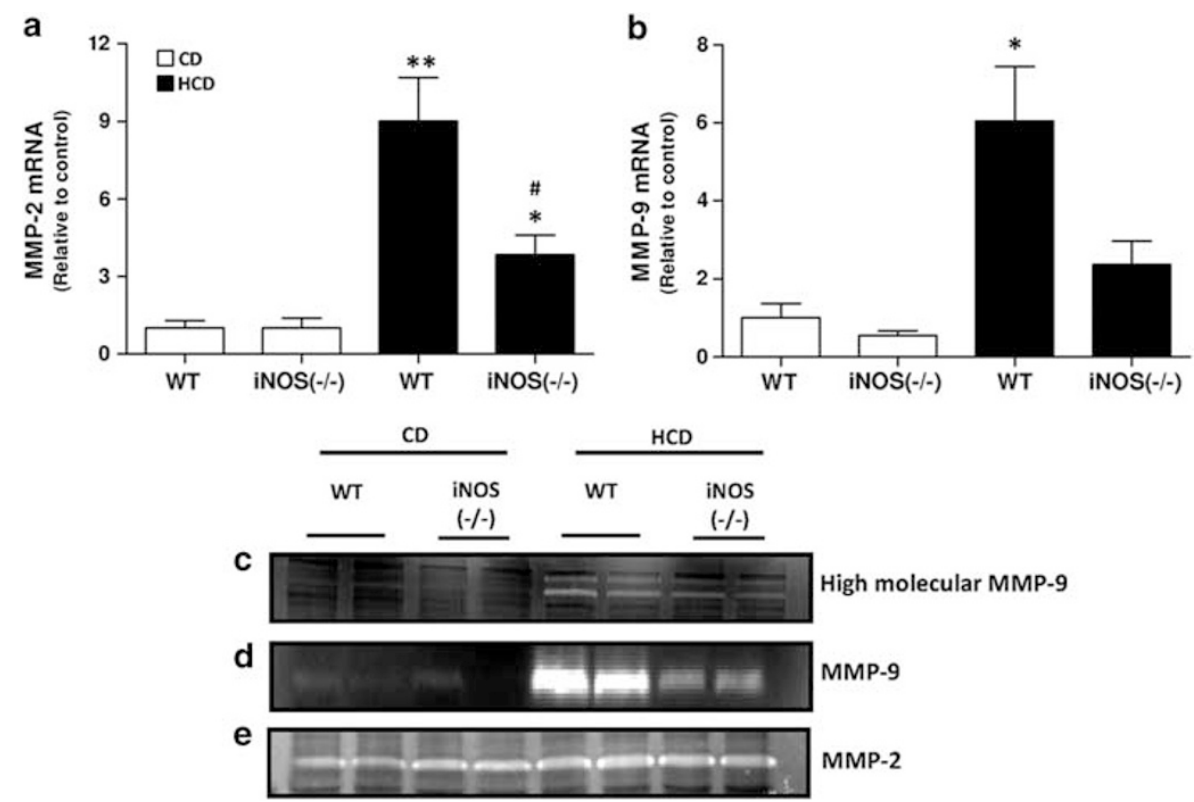

Figure 4 Effects of high-cholesterol diet (HCD) on liver matrix metalloproteinase (MMP)-2 and -9 induction in wild-type (WT) and iNOS-deficient mice (iNOS(-/-)). WT and iNOS-deficient mice fed with control diet (CD) (white bars) or HCD (black bars) for 6 weeks. Hepatic mRNA expression levels of (a) MMP-2 and (b) MMP-9. Activity of (c) high molecular MMP-9, (d) MMP-9, and (e) MMP-2 assessed by gelatin zymography. Results are means \pm s.e.m. ${ }^{*} P \leq 0.05,{ }^{*} P \leq 0.01$ vs WT fed with $C D ;{ }^{\#} P \leq 0.05$ vs WT fed with $\mathrm{HCD}$. 

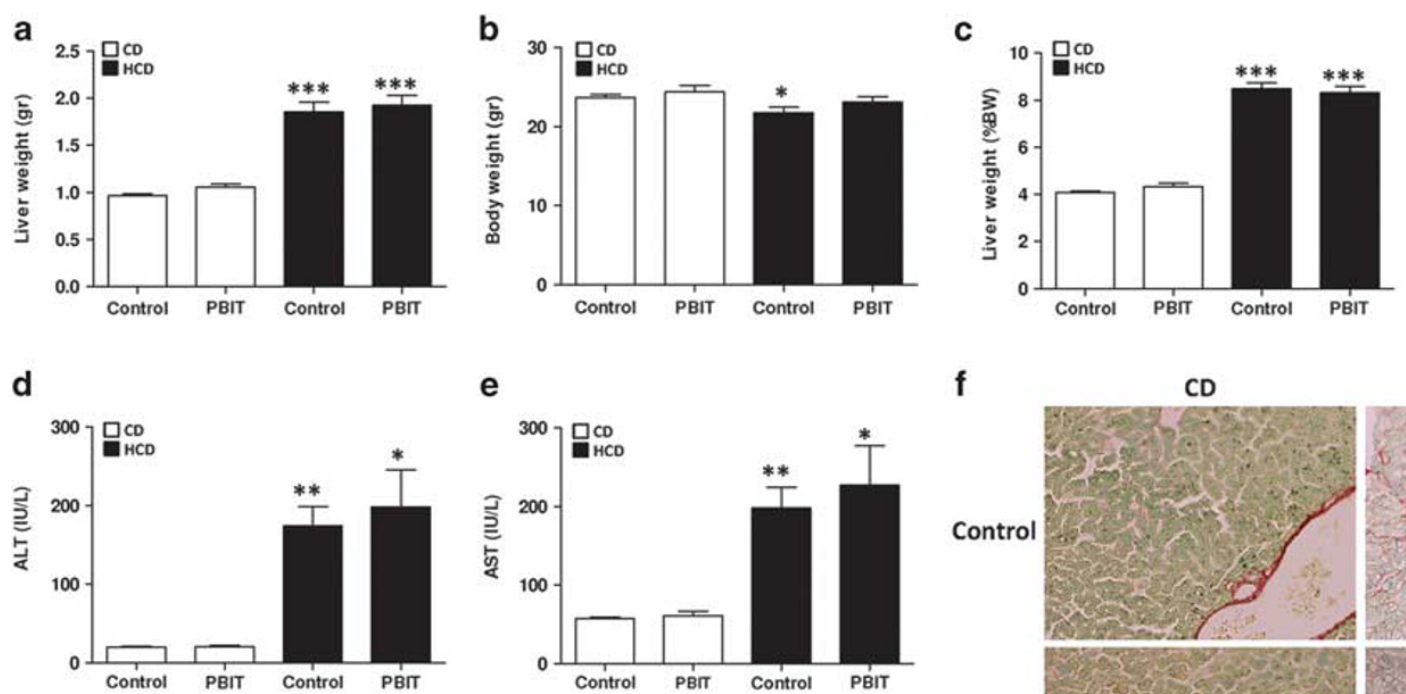

f
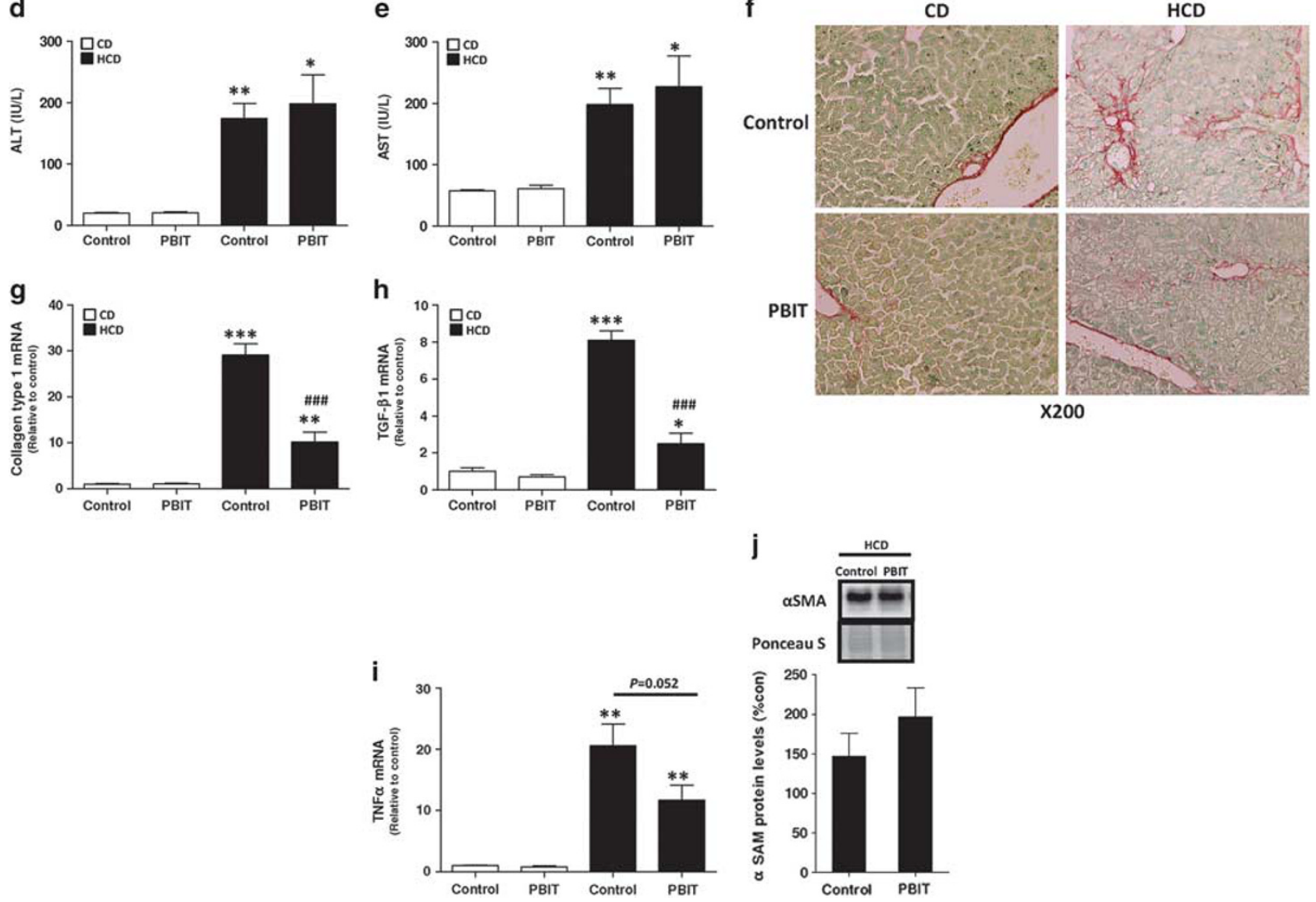

Figure 5 Effects iNOS inhibition by PBIT during high-cholesterol diet (HCD) treatment on liver steatosis, damage, and fibrosis. Control and PBIT-treated mice fed with control diet (CD, white bars) or HCD (black bars) for 6 weeks. (a) Liver weight (g), (b) body weight (BW) (g), (c) liver weight (\% BW), and plasma levels of (d) ALT and (e) AST. (f) Sirius red-stained sections of representative liver samples. Hepatic mRNA expression levels of (g) collagen type 1, (h) transforming growth factor- $\beta 1$ (TGF- $\beta 1$ ), (i) tumor necrosis factor- $\alpha$ (TNF- $\alpha$ ), and $\alpha$-smooth muscle actin ( $\alpha$-SMA) protein levels. Results are means \pm s.e.m. ${ }^{*} P \leq 0.05,{ }^{* *} P \leq 0.01,{ }^{* *} P \leq 0.001$ vs control mice fed with $C D$; ${ }^{\# \# \#} P \leq 0.001$ vs control mice fed with $\mathrm{HCD}$.

based on measurement of plasma liver enzyme levels, was also enhanced in both the groups to a comparable extent (Figure $5 \mathrm{~d}$ and e). Consistent with genetic elimination of iNOS expression, pharmacological inhibition of iNOS reduced HCD-induced liver fibrosis, as illustrated by Sirus Red staining and the expression of collagen type-1 and profibrotic cytokines (Figure 5f-i). However, similar $\alpha \mathrm{SMA}$ levels were observed in control and iNOS-inhibited mice fed with HCD (Figure 5j). Regarding MMP-9, there was a lower induction of gene expression and protein levels in the livers of HCD-fed mice treated with iNOS-specific inhibitor (Figure 6a and b). Overall, these findings provide further evidence to support the important role of iNOS in liver fibrosis caused by consumption of a HCD.

\section{The Role of iNOS in Cholesterol-Induced MMP-9 Expression in HSC-T6 Cells}

Recent evidence indicates that during fibrogenesis HSCs are an important source of MMP-9. ${ }^{13,28}$ Our work also elucidated the role of cholesterol and NO in MMP-9 induction in an in vitro model of HSC-T6 cells. As shown in Figure 7a, MMP-9 expression was significantly increased in HSC-T6 cells incubated with cholesterol. In addition, increased iNOS mRNA and protein levels were observed (Figure $7 \mathrm{~b}$ and $\mathrm{c}$ ). 


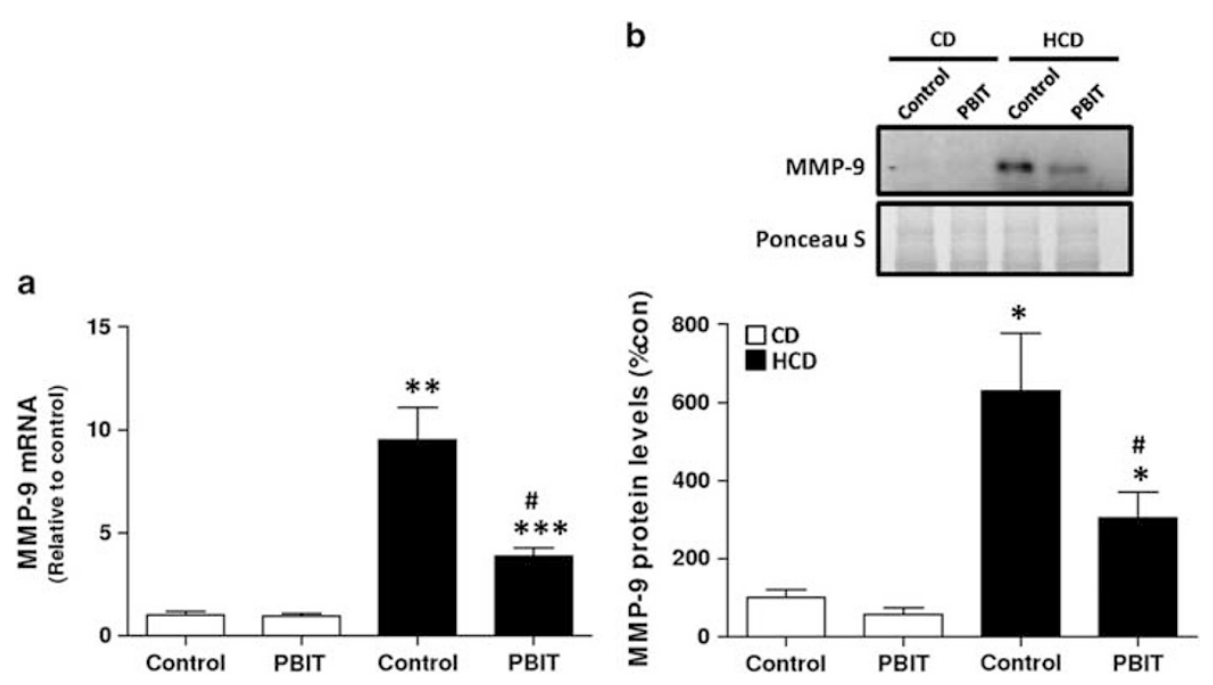

Figure 6 Effects of iNOS inhibition by PBIT during high-cholesterol diet (HCD) treatment on liver matrix metalloproteinase-9 (MMP-9) induction. Control and PBIT-treated mice fed with control diet (CD, white bars) or HCD (black bars) for 6 weeks. (a) Liver mRNA expression and (b) protein levels of MMP-9. Results are means \pm s.e.m. ${ }^{*} P \leq 0.05,{ }^{*} P \leq 0.01,{ }^{*}{ }^{*} P \leq 0.001$ vs control mice fed with $C D ;{ }^{*} P \leq 0.05$ vs control mice fed with $\mathrm{HCD}$.

The involvement of iNOS in cholesterol-induced MMP-9 expression was verified using an iNOS inhibitor. Inhibition of iNOS using L-NAME successfully ameliorated cholesterolinduced MMP-9 expression (Figure 7d). The ability of NO to affect MMP-9 expression was further verified using an NO donor. HSC-T6 cells were treated with an NO donor, which significantly enhanced MMP-9 expression (Figure 7e). These results demonstrate the importance of iNOS-derived NO in MMP-9 induction in HSC-T6 cells.

\section{Effects of HCD on DNA Damage in WT and iNOS-Deficient Mice}

Liver fibrosis has been previously found to be associated with DNA damage. ${ }^{29}$ Recently, both iNOS and MMP activation have separately and together been connected to DNA damage. ${ }^{9,30-34}$ Therefore, it was important to evaluate the effect of HCD on DNA damage. Phosphorylation status of histone 2AX (H2AX) at Ser139 is a sensitive reliable marker of early DNA damage response. ${ }^{35}$ As shown in Figure 8a, phosphorylation of H2AX was significantly higher in HCDfed WT mice than in HCD-fed iNOS-deficient mice and tend to be lower in PBIT-treated mice fed with HCD compared with mice fed with HCD (Supplementary Figure S3). PCNA is an auxiliary factor required for DNA repair. Similar to H2AX phosphorylation status, PCNA levels were also enhanced to a greater extent in HCD-fed WT mice (Figure 8b). These findings indicate augmented DNA damage and attempts to repair damaged tissue in the presence of iNOS during HCD.

\section{DISCUSSION}

The role of iNOS in liver fibrosis is highly controversial. The current study found a profibrotic effect of iNOS following feeding with a HCD. In iNOS-deficient mice and in mice with pharmacological inhibition of iNOS, lower levels of liver fibrosis were observed following the consumption of HCD for 6 weeks. Although the exact mechanism by which iNOS promotes fibrosis progression is still not entirely understood, our results suggest that iNOS has a role in this process through the induction of HIF-1 and MMP-9 and by promoting DNA damage.

Interesting findings were reflected by $\alpha$ SMA levels in iNOSdeficient and iNOS-inhibited mice. Despite a decrease in liver fibrosis, $\alpha$ SMA levels were not reduced in comparison with control animals. This implies that iNOS could have a role in the late phase of HSC activation, during perpetuation, rather than in the activation step. Although $\alpha \mathrm{SMA}$ is a sensitive marker of activated stellate cells, its expression is commonly upregulated even before ECM accumulates. ${ }^{36}$ Indeed, experimental studies have shown a temporal sequence of events with HSC activation preceding liver fibrogenesis. ${ }^{37}$ HSC activation has been demonstrated in patients with NAFLD with variable rates of fibrosis, including greater HSC activation scores relative to the stage of fibrosis. ${ }^{36-39}$ Consistent with this finding, liver biopsies taken from alcoholic patients contained significantly greater numbers of activated HSC than control biopsies, although there was no correlation between numbers of activated HSC and number of Kupffer cells or the extent of fibrosis. ${ }^{40}$ HSC activation and fibrosis in many cases of NASH may be explained by the fact that HSC activation is a dynamic process relative to fibrosis. ${ }^{39}$

Although discrepancies exist, results obtained from alcoholic and non-alcoholic fatty livers suggest HSC activation is associated with severity of steatosis rather than with inflammatory activity or fibrosis. The findings imply that the presence of fat alone can result in liver injury leading to HSC activation. ${ }^{39}$ Therefore, it is logical to suggest that liver fat accumulation induced by the HCD, which was similar in all mice regardless of iNOS status, led to HSC activation. Although 
a

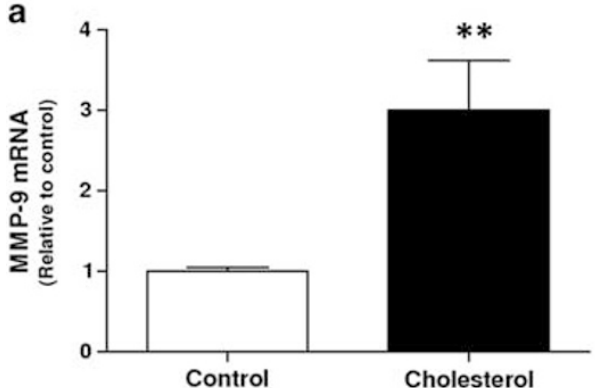

c
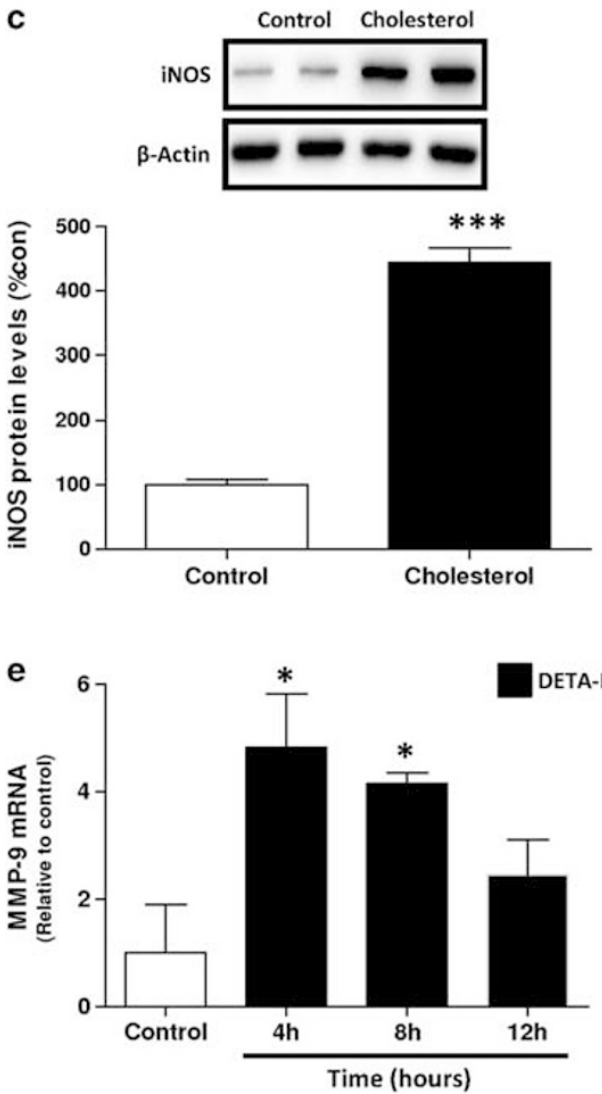

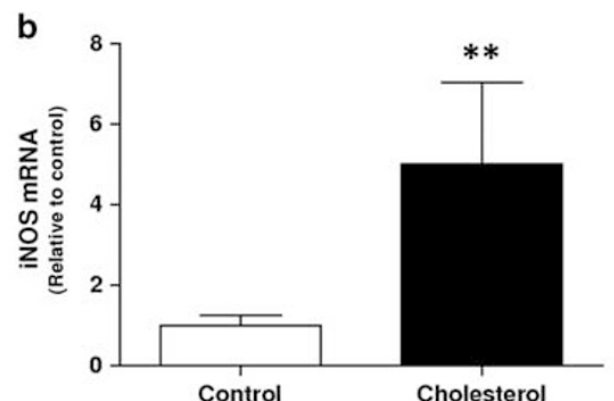

d

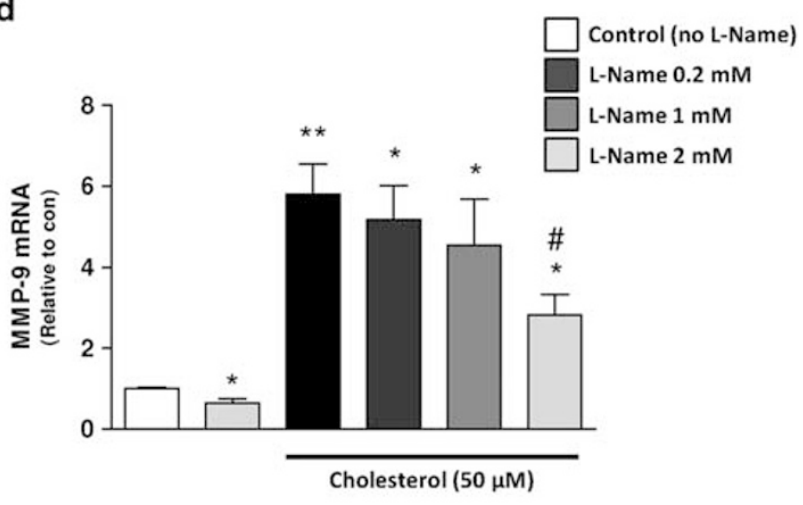

ETA-NO

Figure 7 iNOS-mediated cholesterol induced MMP-9 expression in HSC-T6 cells. (a) iNOS mRNA, (b) protein levels, and (c) MMP-9 mRNA levels in HSCT6 cells incubated with water-soluble cholesterol $(50 \mu \mathrm{M})$ for $24 \mathrm{~h}$. (d) MMP-9 expression levels in HSC-T6 cells incubated with or without water soluble cholesterol in the presence of various concentrations of iNOS inhibitor, L-NAME, or (e) with NO donor, EDTA NONOate, for 4, 8, and 12 h. Results are means \pm s.e.m. ${ }^{*} P \leq 0.05,{ }^{*} P \leq 0.01,{ }^{* * *} P \leq 0.001$ vs control group; ${ }^{*} P \leq 0.05$ vs cholesterol-treated cells.

$\alpha$ SMA staining is commonly used as a marker to evaluate the amount/activity of fibrogenic cells in the liver, recent evidence challenges this paradigm. Magness et al. ${ }^{41}$ provided in vitro and in vivo evidence that there is heterogeneity in HSCs/ myofibroblasts with regard to gene expression. The study elegantly demonstrated that $\alpha \mathrm{SMA}$ and collagen $\alpha 1$ (I) are not always coexpressed in fibrogenic cell types. This further highlights the importance of collagen expression in the liver tissue when assessing liver fibrogenesis. Moreover, it is also important to mention that while the conventional perception is that $\alpha$-actin expression enhances tissue fibrosis, mice lacking $\alpha \mathrm{SMA}$ protein in myofibroblasts have increased renal fibrosis in experimental glomerulonephritis. ${ }^{42}$ This further indicates that $\alpha \mathrm{SMA}$ induction may be a counter-regulatory response to enhanced fibrogenesis. ${ }^{36,42}$

Stimulation of hepatic fibrosis by HCD could be mediated by the activation of HIF-1. HIF- $1 \alpha$ was induced to a greater extent in HCD-fed WT mice compared with iNOS-deficient mice. This result is in accordance with our previous findings in which cholesterol induced the HIF-1 pathway in the liver and was iNOS dependant. ${ }^{23,24}$ Recent data suggest an important role for HIF-1 in the pathogenesis of fibrotic diseases, including liver fibrosis. Indeed, many genes under the regulation of HIF-1 have been implicated in the pathogenesis of liver fibrosis as well as in ECM modifications. ${ }^{43-49}$ HIF-1-deficient mice develop less liver 
a
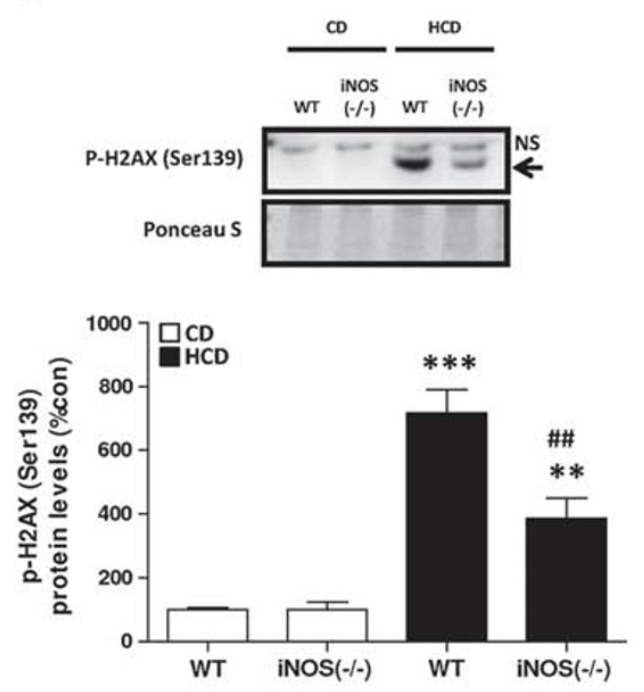

b
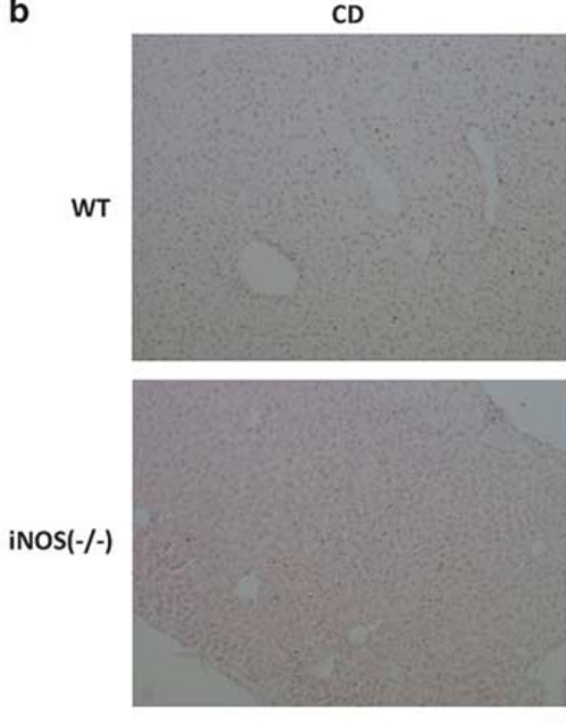
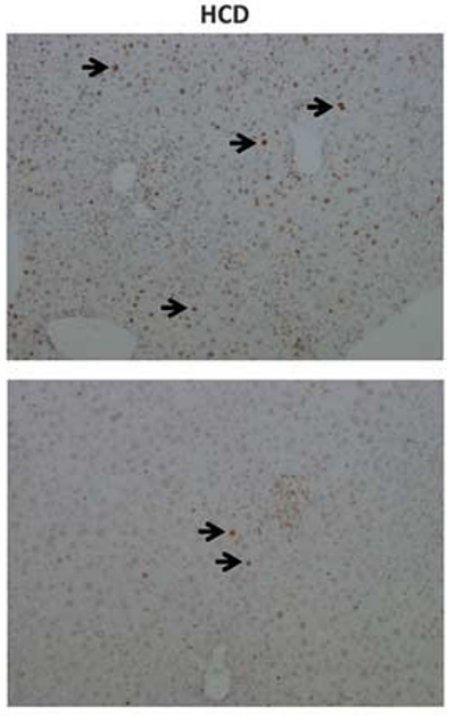

X200

Figure 8 Effects of high-cholesterol diet (HCD) on DNA damage in wild-type (WT) and iNOS-deficient mice (iNOS(-/-)). WT and iNOS-deficient mice fed with control diet (CD) or HCD for 6 weeks. (a) Phosphorylation status of histone 2AX (H2AX) at Ser139 and (b) immunohistochemical staining of proliferating cell nuclear antigen (PCNA) in liver sections. Arrows indicate positive signals. Results are means \pm s.e.m. ${ }^{* *} P \leq 0.01,{ }^{* *} P \leq 0.001$ vs WT fed with CD; ${ }^{\# \#} P \leq 0.01$ vs WT fed with HCD. NS, not specific.

fibrosis following bile duct ligation. ${ }^{46}$ Moon et al. ${ }^{46}$ demonstrated reduced expression of several profibrotic mediators and reduced production of collagenous matrix in HIF-1 liverdeficient mice. Consist with these previous studies, in the present study, HIF-1 activation was accompanied with an increase in PDGF and FGF-2 and a trend towards higher PAI-1 expression. Taken together, it appears that iNOS serves as an important link in cholesterol-induced liver fibrosis.

iNOS induction regulated MMP-9 activation in vivo as well as in vitro. MMPs are a family of zinc-containing enzymes involved in degradation and remodeling of the components of the ECM under both physiological and pathophysiological conditions. ${ }^{50}$ Among this family, MMP-9 represents the largest and most complex member. ${ }^{51}$ Uncontrolled increases of MMP-9 activity have been implicated in contributing to tissue degradation in many pathological conditions, including scarring, following myocardial injury, central nervous system injury, lung injury, kidney disease, and liver injury. ${ }^{52}$ The role of MMP-9 in tissues and specifically in liver fibrogenesis is not entirely understood and is widely debated. Yet, compelling evidence indicates that this MMP may have an important role in this process. ${ }^{26,28,53}$ Supporting the notion that MMP-9 may promote liver fibrosis, studies conducted in MMP-9deficient mice found attenuated liver fibrosis in these mice following liver injury. Moreover, clinical studies discovered a link between the increased levels of MMPs, including MMP-9, and fragments of type-IV collagen in cirrhosis. ${ }^{53}$ Furthermore, liver MMP-9 expression and activity have also been associated with the stage of fibrosis in chronic hepatitis C. ${ }^{54}$ In a study conducted by Kamari and colleagues, ${ }^{4}$ decreased liver fibrosis in interleukin-1 (IL-1) $\alpha$-deficient mice fed with atherogenic diet (high-fat/cholesterol and cholate diet, HFHCD) was associated with lower MMP-9 expression independent of liver steatosis. These results, together with our present findings, illustrate the positive association between MMP-9 expression and liver fibrosis in response to high-cholesterol/cholate consumption. Chen et al. ${ }^{55}$ also demonstrated an increase in MMP-9 in WT but not in their iNOS KO mice following the consumption of HFHCD. However, in their study, an increase in liver fibrosis was observed in iNOS KO mice compared with WT mice. The reason for this discrepancy is unknown. It is possible that the addition of fat to the diet may alter the expression and activity of iNOS and/or other factors, which modifies physiological outcome. Moreover, in the work of Chen et al., ${ }^{55}$ the lack of protein expression, following the ablation of the iNOS gene was not demonstrated. Thus, it is uncertain whether iNOS activity and its signaling effects were utterly abolished. This assessment is critical given that NO production at different levels produces different effects.

The mechanism by which MMP-9 participates in the activation of liver fibrogenesis is only partially understood. However, several potential mechanisms have been proposed. Han et al. ${ }^{28}$ suggested that MMPs, and their mediated degradation of ECM in the space of Disse, are essential for fibrotic activation of HSC in ECM and in liver fibrogenesis. According to this hypothesis, particular ECM components maintain the phenotype of quiescent HSCs in normal liver. Therefore, matrix breakdown by MMPs can contribute to the activation of HSC. ${ }^{28}$

Although it was initially believed that MMPs were solely involved in matrix turnover and degradation, recent studies 
have discovered a number of novel and unexpected substrates for these MMPs. ${ }^{25}$ These findings suggest new biological roles of MMPs including the active involvement in the inflammatory process. MMP-9 may have a role in modulation of inflammation through proteolytic activation of proinflammatory cytokines/chemokines including IL- $1 \beta$, TGF- $\beta$, and membrane-bound TNF $\alpha .{ }^{56-58}$

The relationship between iNOS-induced NO and MMP-9 induction is highly complex and has received much attention in the last two decades. ${ }^{59}$ Under inflammatory conditions there is a concurrent upregulation of both iNOS and MMP-9. Still, the crosstalk between these enzymes remains to be clarified. Elevated levels of $\mathrm{NO}$ were shown to positively regulate MMP-9 activation on several levels: NO induces MMP-9 activation directly and indirectly, increases its release and distribution and also promotes MMP-9 expression via cGMP in both dependent and independent manners. Although many studies, including the present study, provide evidence for the activation of MMP-9 by NO, additional evidence supporting the inhibitory role of NO on MMP-9 activation also exists. ${ }^{59}$ The conflicting results as to whether NO enhances or inhibits MMP-9 illustrates the complexity of the interactions at the molecular level.

iNOS has been associated with the pathophysiology of certain inflammatory disorders by inducing DNA damage or hindering DNA repair. ${ }^{34}$ Hepatic fibrosis is initiated by damage to hepatocytes that results in the recruitment of inflammatory cells and the activation of kupffer cells, which subsequently lead to enhanced production of profibrotic cytokines such as TNF $\alpha$ and TGF- $\beta,{ }^{60}$ DNA damage is a common feature in various forms of chronic liver diseases. ${ }^{29,61,62}$ DNA damage was evident during liver fibrosis and was also shown to correlate with liver fibrosis as assessed by serum hyaluronic acid, platelet count, and histological staining score. ${ }^{29,62-65}$ In the current study, DNA damage, as evident by higher H2AX phosphorylation on Ser139 as well as the accumulation of PCNA, was enhanced in WT mice fed with HCD compared with iNOSdeficient mice. Several lines of evidence support the role for iNOS-induced $\mathrm{NO}$ in the generation of oxidative and nitrosative DNA damage. $\mathrm{NO}$ or its oxidation products $\mathrm{N}_{2} \mathrm{O}_{3}$ and peroxynitrite were shown to induce DNA damage through direct strand breaks and base modification. ${ }^{33,66}$ Interestingly, the involvement of MMP-9 in iNOS-induced DNA damage was also recently documented. ${ }^{31}$ Using a model of peribiliary fibrosis, caused by chronic infection with opsthorchis viverrini, Prakobwong et al. have shown that MMP-9 expression is associated with the accumulation of peribiliary fibrosis in conjugation of iNOS and Racl activation. In their study, NOinduced MMP-9 activation mediated Rac1 expression, which led to reactive oxygen and nitrogen species generation and DNA damage. The authors suggested that iNOS and MMP-9 induction promoted the accumulation of fibrosis and potentiated DNA damage and tumor progression. ${ }^{31}$

In summary, the current study demonstrated that HCD promoted liver damage and liver fibrosis, which were potentiated by iNOS activation. iNOS activation was associated with the induction of several pathways that are involved in the development of liver fibrosis, HIF-1, and MMP-9 along with the induction of DNA damage. All of which appear to be a part of the pathologic process. Therefore, given the critical role of iNOS in the development of liver fibrosis, long-term inhibition of iNOS in cases of liver steatotis may have therapeutic benefits.

Supplementary Information accompanies the paper on the Laboratory Investigation website (http://www.laboratoryinvestigation.org)

\section{ACKNOWLEDGMENTS}

This study was supported a by grant no. 371/12 from the Israel Science Foundation.

\section{DISCLOSURE/CONFLICT OF INTEREST}

The authors declare no conflict of interest.

1. Bataller R, Brenner DA.. Liver fibrosis. J Clin Invest 2005;115:209-218.

2. Ismail MH, Pinzani M. Reversal of liver fibrosis. Saudi J Gastroenterol 2009;15:72-79.

3. Charlton M.. Fatty liver disease; NASH and related disorders. Gastroenterology 2005;129:1801-1802.

4. Kamari Y, Shaish A, Vax E et al. Lack of interleukin-1alpha or interleukin-1beta inhibits transformation of steatosis to steatohepatitis and liver fibrosis in hypercholesterolemic mice. J Hepatol 2011;55: 1086-1094.

5. Wang W, Zhao C, Zhou J et al. Simvastatin ameliorates liver fibrosis via mediating nitric oxide synthase in rats with non-alcoholic steatohepatitis-related liver fibrosis. PLoS One 2013;8:e76538.

6. Farrell GC, van Rooyen D. Liver cholesterol: is it playing possum in NASH? Am J Physiol Gastrointest Liver Physiol 2012;303:G9-G11.

7. Farrell GC, van Rooyen D, Gan L et al. NASH is an inflammatory disorder: pathogenic, prognostic and therapeutic implications. Gut Liver 2012;6:149-171.

8. Teratani T, Tomita K, Suzuki T et al. A high-cholesterol diet exacerbates liver fibrosis in mice via accumulation of free cholesterol in hepatic stellate cells. Gastroenterology 2012;142:152-164 e110.

9. Tomita K, Teratani T, Suzuki T et al. Free cholesterol accumulation in hepatic stellate cells: mechanism of liver fibrosis aggravation in nonalcoholic steatohepatitis in mice. Hepatology 2014;59:154-169.

10. Ioannou GN, Morrow OB, Connole ML et al. Association between dietary nutrient composition and the incidence of cirrhosis or liver cancer in the United States population. Hepatology 2009;50:175-184.

11. Van Rooyen DM, Gan LT, Yeh MM et al. Pharmacological cholesterol lowering reverses fibrotic NASH in obese, diabetic mice with metabolic syndrome. J Hepatol 2013;59:144-152.

12. Diesen DL, Kuo PC. Nitric oxide and redox regulation in the liver: part II. Redox biology in pathologic hepatocytes and implications for intervention. J Surg Res 2011;167:96-112.

13. Ergun $Y$, Kurutas EB, Ozdil B et al. Evaluation of nitrite/nitrate levels in relation to oxidative stress parameters in liver cirrhosis. Clin Res Hepatol Gastroenterol 2011;35:303-308.

14. Mayoral P, Criado M, Hidalgo F et al. Effects of chronic nitric oxide activation or inhibition on early hepatic fibrosis in rats with bile duct ligation. Clin Sci (Lond) 1999;96:297-305.

15. Wei $\mathrm{CL}$, Hon WM, Lee $\mathrm{KH}$ et al. Chronic administration of aminoguanidine reduces vascular nitric oxide production and attenuates liver damage in bile duct-ligated rats. Liver Int 2005;25:647-656.

16. Criado $\mathrm{M}$, Flores $\mathrm{O}$, Vazquez $\mathrm{MJ}$ et al. Role of prostanoids and nitric oxide inhibition in rats with experimental hepatic fibrosis. J Physiol Biochem 2000;56:181-188.

17. Moal F, Veal N, Vuillemin E et al. Hemodynamic and antifibrotic effects of a selective liver nitric oxide donor V-PYRRO/NO in bile duct ligated rats. World J Gastroenterol 2006;12:6639-6645. 
18. Lukivskaya O, Patsenker $\mathrm{E}$, Lis R et al. Inhibition of inducible nitric oxide synthase activity prevents liver recovery in rat thioacetamide-induced fibrosis reversal. Eur J Clin Invest 2008;38:317-325.

19. Patel RP, Levonen A, Crawford JH et al. Mechanisms of the pro- and anti-oxidant actions of nitric oxide in atherosclerosis. Cardiovasc Res 2000;47:465-474.

20. Folch J, Lees M, Sloane Stanley GH.. A simple method for the isolation and purification of total lipides from animal tissues. J Biol Chem 1957;226:497-509.

21. Anavi S, Harmelin NB, Madar Z et al. Oxidative stress impairs HIF1alpha activation: a novel mechanism for increased vulnerability of steatotic hepatocytes to hypoxic stress. Free Radic Biol Med 2012;52: 1531-1542.

22. Kupai K, Szucs G, Cseh S et al. Matrix metalloproteinase activity assays: Importance of zymography. J Pharmacol Toxicol Methods 2010;61: 205-209.

23. Anavi S, Hahn-Obercyger M, Madar $Z$ et al. Mechanism for HIF-1 activation by cholesterol under normoxia: a redox signaling pathway for liver damage. Free Radic Biol Med 2014;71:61-69.

24. Anavi S, Hahn-Obercyger M, Margalit R et al. A novel antihypoglycemic role of inducible nitric oxide synthase in liver inflammatory response induced by dietary cholesterol and endotoxemia. Antioxid Redox Signal 2013;19:1889-1901.

25. Giannandrea M, Parks WC. Diverse functions of matrix metalloproteinases during fibrosis. Dis Model Mech 2014;7:193-203.

26. Han YP. Matrix metalloproteinases, the pros and cons, in liver fibrosis. J Gastroenterol Hepatol 2006;21():S88-S91.

27. Garvey EP, Oplinger JA, Tanoury GJ et al. Potent and selective inhibition of human nitric oxide synthases. Inhibition by non-amino acid isothioureas. J Biol Chem 1994;269:26669-26676.

28. Han YP, Yan C, Zhou L et al. A matrix metalloproteinase-9 activation cascade by hepatic stellate cells in trans-differentiation in the threedimensional extracellular matrix. J Biol Chem 2007;282:12928-12939.

29. Tanaka H, Fujita N, Sugimoto R et al. Hepatic oxidative DNA damage is associated with increased risk for hepatocellular carcinoma in chronic hepatitis C. Br J Cancer 2008;98:580-586.

30. Farina AR, Mackay ARGelatinase B/MMP-9 in Tumour Pathogenesis and ProgressionCancers (Basel) 2014;6:240-296.

31. Prakobwong S, Yongvanit P, Hiraku $Y$ et al. Involvement of MMP-9 in peribiliary fibrosis and cholangiocarcinogenesis via Rac1-dependent DNA damage in a hamster model. Int J Cancer 2010;127:2576-2587.

32. Hill JW, Poddar R, Thompson JF et al. Intranuclear matrix metalloproteinases promote DNA damage and apoptosis induced by oxygen-glucose deprivation in neurons. Neuroscience 2012;220: 277-290.

33. Murata $\mathrm{M}$, Thanan $\mathrm{R}, \mathrm{Ma} \mathrm{N}$ et al. Role of nitrative and oxidative DNA damage in inflammation-related carcinogenesis. J Biomed Biotechnol 2012;2012:623019.

34. Menon VP, Sudheer AR. Antioxidant and anti-inflammatory properties of curcumin. Adv Exp Med Biol 2007;595:105-125.

35. Sharma A, Singh K, Almasan A. Histone H2AX phosphorylation: a marker for DNA damage. Methods Mol Biol 2012;920:613-626.

36. Friedman SL. Hepatic stellate cells: protean, multifunctional, and enigmatic cells of the liver. Physiol Rev 2008;88:125-172.

37. Feldstein AE, Papouchado BG, Angulo P et al. Hepatic stellate cells and fibrosis progression in patients with nonalcoholic fatty liver disease. Clin Gastroenterol Hepatol 2005;3:384-389.

38. Cortez-Pinto H, Baptista A, Camilo ME et al. Hepatic stellate cell activation occurs in nonalcoholic steatohepatitis. Hepatogastroenterology 2001;48:87-90.

39. Washington $\mathrm{K}$, Wright $\mathrm{K}$, Shyr $\mathrm{Y}$ et al. Hepatic stellate cell activation in nonalcoholic steatohepatitis and fatty liver. Hum Pathol 2000;31: 822-828.

40. Reeves HL, Burt AD, Wood S et al. Hepatic stellate cell activation occurs in the absence of hepatitis in alcoholic liver disease and correlates with the severity of steatosis. J Hepatol 1996;25:677-683.

41. Magness ST, Bataller R, Yang $L$ et al. A dual reporter gene transgenic mouse demonstrates heterogeneity in hepatic fibrogenic cell populations. Hepatology 2004;40:1151-1159.

42. Friedman SL. Mechanisms of hepatic fibrogenesis. Gastroenterology 2008;134:1655-1669.
43. Haase $\mathrm{VH}$. Hypoxia-inducible factor signaling in the development of kidney fibrosis. Fibrogenesis Tissue Repair 2012;5:S16.

44. Higgins DF, Kimura K, Bernhardt WM et al. Hypoxia promotes fibrogenesis in vivo via HIF-1 stimulation of epithelial-tomesenchymal transition. J Clin Invest 2007;117:3810-3820.

45. Lokmic Z, Musyoka J, Hewitson TD et al. Hypoxia and hypoxia signaling in tissue repair and fibrosis. Int Rev Cell Mol Biol 2012;296: 139-185.

46. Moon JO, Welch TP, Gonzalez FJ et al. Reduced liver fibrosis in hypoxiainducible factor-1alpha-deficient mice. Am J Physiol Gastrointest Liver Physiol 2009;296:G582-G592.

47. Nath B, Szabo G. Hypoxia and hypoxia inducible factors: diverse roles in liver diseases. Hepatology 2012;55:622-633.

48. Paternostro C, David E, Novo E et al. Hypoxia, angiogenesis and liver fibrogenesis in the progression of chronic liver diseases. World J Gastroenterol 2010;16:281-288.

49. Rosmorduc O, Housset C. Hypoxia: a link between fibrogenesis, angiogenesis, and carcinogenesis in liver disease. Semin Liver Dis 2010;30:258-270.

50. Li H, Mittal A, Makonchuk DY et al. Matrix metalloproteinase-9 inhibition ameliorates pathogenesis and improves skeletal muscle regeneration in muscular dystrophy. Hum Mol Genet 2009;18: 2584-2598.

51. Van den Steen PE, Dubois B, Nelissen I et al. Biochemistry and molecular biology of gelatinase B or matrix metalloproteinase-9 (MMP-9). Crit Rev Biochem Mol Biol 2002;37:375-536.

52. Loiselle $\mathrm{AE}$, Frisch $\mathrm{BJ}$, Wolenski $\mathrm{M}$ et al. Bone marrow-derived matrix metalloproteinase- 9 is associated with fibrous adhesion formation after murine flexor tendon injury. PLoS One 2012;7:e40602.

53. Gieling RG, Wallace K, Han YP. Interleukin-1 participates in the progression from liver injury to fibrosis. Am J Physiol Gastrointest Liver Physiol 2009;296:G1324-G1331.

54. Gadd VL, Melino M, Roy S et al. Portal, but not lobular, macrophages express matrix metalloproteinase-9: association with the ductular reaction and fibrosis in chronic hepatitis C. Liver Int 2013;33:569-579.

55. Chen Y, Hozawa S, Sawamura $S$ et al. Deficiency of inducible nitric oxide synthase exacerbates hepatic fibrosis in mice fed high-fat diet. Biochem Biophys Res Commun 2005;326:45-51.

56. Heilpern AJ, Wertheim W, He J et al. Matrix metalloproteinase 9 plays a key role in lyme arthritis but not in dissemination of Borrelia burgdorferi. Infect Immun 2009;77:2643-2649.

57. Birrell MA, Wong S, Dekkak A et al. Role of matrix metalloproteinases in the inflammatory response in human airway cell-based assays and in rodent models of airway disease. J Pharmacol Exp Ther 2006;318:741-750.

58. Jeong S, Ledee DR, Gordon GM et al. Interaction of clusterin and matrix metalloproteinase- 9 and its implication for epithelial homeostasis and inflammation. Am J Pathol 2012;180:2028-2039.

59. O'Sullivan S, Medina C, Ledwidge $M$ et al. Nitric oxide-matrix metaloproteinase-9 interactions: biological and pharmacological significance-NO and MMP-9 interactions. Biochim Biophys Acta 2014; 1843:603-617.

60. Shimizu I, Shimamoto N, Saiki K et al. Lipid Peroxidation in Hepatic Fibrosis 2012.

61. Ichiba M, Maeta Y, Mukoyama T et al. Expression of 8-hydroxy-2'deoxyguanosine in chronic liver disease and hepatocellular carcinoma. Liver Int 2003;23:338-345.

62. Daugherity EK, Balmus G, Al Saei A et al. The DNA damage checkpoint protein ATM promotes hepatocellular apoptosis and fibrosis in a mouse model of non-alcoholic fatty liver disease. Cell Cycle 2012;11: 1918-1928.

63. Bopp A, Wartlick F, Henninger C et al. Rac1 modulates acute and subacute genotoxin-induced hepatic stress responses, fibrosis and liver aging. Cell Death Dis 2013;4:e558.

64. Yue HY, Yin C, Hou JL et al. Hepatocyte nuclear factor 4alpha attenuates hepatic fibrosis in rats. Gut 2010;59:236-246.

65. Kim MR, Kim HS, Lee MS et al. Cell cycle protein profile of the hepatic stellate cells(HSCs)in dimethylnitrosamine-induced rat hepatic fibrosis. Exp Mol Med 2005;37:335-342.

66. Hughes KJ, Meares GP, Chambers KT et al. Repair of nitric oxidedamaged DNA in beta-cells requires JNK-dependent GADD45alpha expression. J Biol Chem 2009;284:27402-27408. 